Article

\title{
Developing a Modified Umbrella Index for Conservation of Macroinvertebrate Diversity in Taizi River Basin, China
}

\author{
Xin Gao ${ }^{1,2}$, Hai-yu Ding ${ }^{3} \mathbb{D}$, Rui Xia ${ }^{1,2}$, Hui Wang ${ }^{1,2}$, Qian-qian Kou ${ }^{1,2}$ and Sen Ding ${ }^{1,2, *}$ \\ 1 State Key Laboratory of Environmental Criteria and Risk Assessment, Chinese Research Academy of \\ Environmental Sciences, Beijing 100012, China; gaoxin@craes.org.cn (X.G.); xiarui@creas.org.cn (R.X.); \\ huiw06@163.com (H.W.); kouqianqian123@126.com (Q.-q.K.) \\ 2 Laboratory of Riverine Ecological Conservation and Technology, Chinese Research Academy of \\ Environmental Sciences, Beijing 100012, China \\ 3 Department of Ecology and Ecosystem Management, Technische Universitaet Muenchen, \\ Freising-Weihenstephan 85354, Germany; haiyu.ding@gmail.com \\ * Correspondence: bearnaise@163.com
}

Received: 8 January 2020; Accepted: 5 March 2020; Published: 19 March 2020

\begin{abstract}
Conservation strategies for a reliable set of umbrella species should benefit many co-occurring species and will improve conservation efficiency. The umbrella index (UI) is increasingly applied for umbrella species selection in different ecosystems. We developed a modified river UI to select potential macroinvertebrate umbrella species with a combination of 69 sites in the Taizi River Basin of northeast China. Calculation of UI and comparison of biotic indices between sites of presence and absence of umbrella species were performed to make the final umbrella species list. The umbrella scheme, based on the proportion and composition of sites supporting the confirmed umbrella species, was introduced to illustrate the conservation effectiveness. A total of eight umbrella species were obtained and all of them were aquatic insects, such as caddisfly and mayfly larva. Umbrella schemes supporting the top umbrella species, hosted the majority of co-occurring species and only $7 \%$ of beneficiary species were missed by the umbrella schemes of $70 \%$ effort. The positive relationship between abundance of co-occurring species and umbrella species, validated the ability of umbrella species to confer protection and co-existence of co-occurring species, and thus indicated the effectiveness of umbrella species conservation. Co-occurring species were located close to umbrella species in ordinations, suggesting they respond to similar environmental variables characterized by high flow velocity, dissolved oxygen and pebble-covered substrate. On account of good performance of umbrella schemes in our study, UI with further improving methods should be promoted for selection of umbrella species and decision for optimizing of conservation sites in the future.
\end{abstract}

Keywords: macroinvertebrate; umbrella index; umbrella species; biodiversity conservation; Taizi River Basin

\section{Introduction}

In conservation, monitoring and evaluating all species in an area will cost excessive expenditure of research time, money and personnel [1-3]. Therefore, conservation biologists have proposed "surrogate species" to provide a shortcut to protect biological diversity and habitat management [4-6]. Among them, the umbrella species is an appropriate kind of surrogate species to prioritize habitat remnants for conservation [7-9]. Wilcox first proposed the idea of umbrella species and believed that a critical factor in selecting "an umbrella species is to choose a suitable target species whose habitat requirements can cover other species, thus the protection of the target species benefits co-occurring 
species" [10]. Thus, protecting a reliable set of umbrella species might improve conservation efficiency from minimal conservation efforts and resources [11].

In the early stage of concept development, mammals were considered as the suitable umbrella species because they had a large home range in which many co-occurring species lived [10]. This assumption led to the assertion that an umbrella species should have a large home range or body size because of a presumptive positive relation between home range and body size for birds and mammals $[10,12,13]$. However, Branton and Richardson have shown that mammalian lager body size has little relation to relatively high species richness or abundance of co-occurring species [14]. Subsequently, the concept of umbrella species has been expanded to include any taxon whose conservation serves to protect other co-occurring species [11,15]. The attention has expanded from terrestrial ecosystems to aquatic ecosystems as well as objects of study from land animals to aquatic organisms [16-20].

The concept of umbrella species has played an important role in aquatic conservation [21], despite the fact that it is rarely applied in aquatic ecosystems [15]. For example, aquatic umbrella species may not only determine areas of priority in marine and freshwater ecosystems conservation [22,23], but also have implications for freshwater integrity assessments in Europe (e.g., Water Framework Directive; see [24]) and the USA (e.g., Environmental Monitoring and Assessment Program; see [25]). Like the applications in terrestrial ecosystems, aquatic species with large home ranges such as fishes are often considered good candidates for umbrella species $[5,17,20]$. In the case where characteristic vertebrates species were absent, invertebrates have served as umbrella species. Butterflies (Lepidoptera) have been most commonly assigned as umbrella species in terrestrial systems [26]. The effectiveness of dragonflies (Odonata) as umbrella species in wetland ecosystems has been studied [18]. Given their dependence on integrated watersheds, ease of sampling and ubiquity in habitats, aquatic invertebrates have been under the spotlight for their effectiveness as umbrella species for aquatic conservation [27,28].

The method of selecting umbrella species is often based on strong empirical evidence that justifies their usage. Rare or commercial species deserve protection on their own merit. However, these methods may not be effective at selecting umbrella species. For example, rare species may co-occur with few other species [29]. To get around this, the umbrella index (UI) was proposed and used to screen potential umbrella species in an eco-region according to objective ecological criteria [11]. This index has also been successfully used on birds and butterflies [11,30,31]. The UI is based on three criteria, i.e., percentage of co-occurring species, degree of ubiquity and sensitivity to human disturbance $[11,30]$. Rareness and sympatry are easily quantifiable based on monitoring data. The environmental sensitivity, though, is measured by various life history parameters which are obtained with qualitative manual scoring method [11]. These life history parameters for birds or butterflies are also difficult to apply directly to evaluate the sensitivity of aquatic organisms, because such data were not available for aquatic life. Moreover, the umbrella species concept and the UI have received little attention with respect to river ecosystems and aquatic taxa.

In present research, we applied this method to aquatic invertebrates and used the tolerance values (TVs), which reflect the ability to survive in interference environment [32], to quantify sensitivity of invertebrates to human disturbance. The TVs are not only quantitative results based on weighted averaging approach [33], but also widely used in the studies of benthic ecology [32,34]. Additionally, it is important to balance the trade-off between available resources (e.g., funding) and protection levels for co-occurring species while selecting umbrella species. For example, if a potential umbrella species has a wide distribution range where conservation actions should be focused, but the cost of conservation effort is also enormous, it would still be difficult to adopt the conservation practice. Therefore, umbrella species with a smaller distribution may be used for conservation management [18]. Hence, the importance of co-occurrence on various habitats, TVs of individual species and protection efforts as a basis for scaling up to river conservation practice, were studied among macroinvertebrates in this study, addressing the following questions: (i) how to develop a river-type UI and define potential 
umbrella species of macroinvertebrate; (ii) how to evaluate the protection levels potentially offered by diverse umbrella schemes when different potential umbrella species were considered?

\section{Methods}

\subsection{Study Area}

The Taizi River Basin is located between $122^{\circ} 26^{\prime}-124^{\circ} 53^{\prime}$ E and $40^{\circ} 29^{\prime}-41^{\circ} 39^{\prime} \mathrm{N}$ (Figure 1), in the Liaoning province of northeast China. The main stem and prime tributaries flow a total of $413 \mathrm{~km}$ and total drainage area is $1.39 \times 10^{4} \mathrm{~km}^{2}$. Multi-year average air temperature ranges from 2.3 to $10.0^{\circ} \mathrm{C}$. Annual precipitation amount in the basin ranges from 655 to $954 \mathrm{~mm}$, and the mean annual runoff is approximately $4.50 \times 10^{9} \mathrm{~m}^{3}$, concentrating from June to September. Vegetation including forest and pasture account for more than $50 \%$ of the total drainage area in the upstream areas and agricultural land is mainly allocated in the mid and downstream areas. Anthropogenic activities increased from the upstream to downstream areas along with the urbanization and increasing farmland in the Taizi River Basin, also it made a gradient-varying disturbance intensity which resulted in a declining habitat quality and biodiversity gradually [35]. The data of corresponding species composition along with gradient disturbance can be collected, especially which type of macroinvertebrate species preferred the rougher substrate in a lotic stream, and sandy substrate in a lentic river. It helped us to analyze the habitat demand for each sensitive and tolerant species by the relative occurrence ratio and abundance in different environmental conditions.

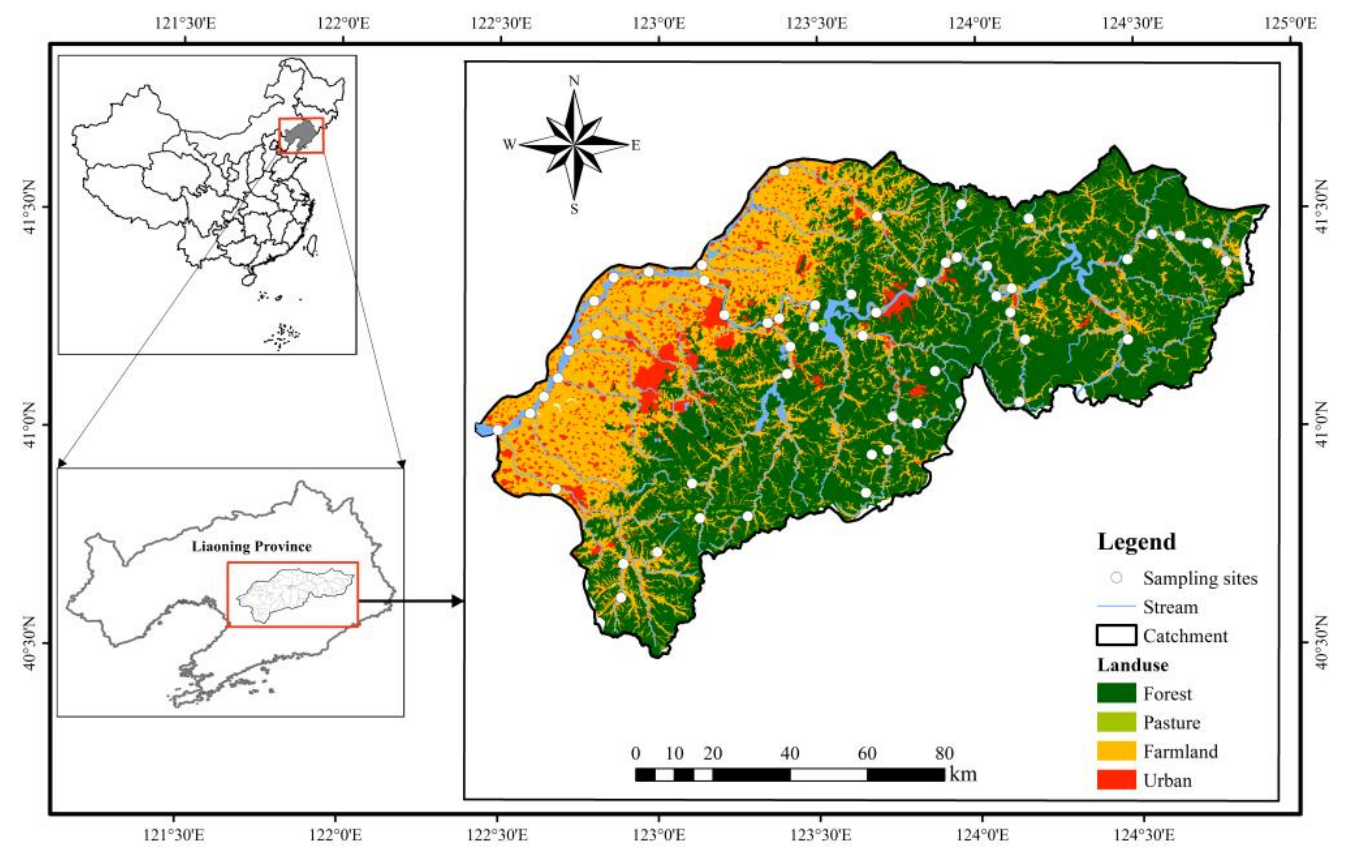

Figure 1. Map of sampling sites in the Taizi River Basin.

\subsection{Macroinvertebrate Sampling}

All the field samplings were performed between 9 a.m. and 4 p.m. as follows: firstly, a $100 \mathrm{~m}$ reach far from artificial structures, such as bridges, was chosen to perform the sampling. Secondly, habitat types were assessed by a different combination with flow velocity, water depth and substrate type and three replicates at each reach were sampled. Thirdly, the Surber net $\left(0.09 \mathrm{~m}^{2}\right.$ in area, with $500 \mu \mathrm{m}$ mesh size) sampling was conducted by the same person to guarantee the consistency of the sampling. Each sample was separately put into a $500 \mathrm{ml}$ bottle and preserved in alcohol (70\%). In laboratory, all the individuals were sorted, counted and identified to the genus or species level except for Chironomidae 
midges, which were only identified to subfamily level, Oligochaetes and Nematodes were identified to class level [36].

\subsection{Environmental Characteristics Analysis}

We used the direct reading current meter (FP-201, Geotech Environmental Equipment, Inc., Denver, CO, USA) to measure the flow velocity (0.6 time of water depth) and depth in situ. Substrates consisting of boulder, cobble, pebble, gravel and sand were identified for each site. A total of 14 chemical parameters, including water temperature (Temp), $\mathrm{pH}$, dissolved oxygen (DO), suspended solids (SS), total dissolved solids (TDS), electrical conductivity (EC), 5 day biological oxygen demand $\left(\mathrm{BOD}_{5}\right)$, permanganate index $\left(\mathrm{COD}_{\mathrm{Mn}}\right)$, chemical oxygen demand $\left(\mathrm{COD}_{\mathrm{Cr}}\right)$, total phosphorus $(\mathrm{TP})$, total nitrogen $(\mathrm{TN})$, ammonia-nitrogen $\left(\mathrm{NH}_{3}-\mathrm{N}\right)$, nitrate nitrogen $\left(\mathrm{NO}_{3}-\mathrm{N}\right)$ and nitrite nitrogen $\left(\mathrm{NO}_{2}-\mathrm{N}\right)$, were monitored for each site were measured. Temp, $\mathrm{pH}$, DO, TDS and EC were directly measured in situ with a hand-held YSI multi-parameter instrument (YSI-80, YSI Inc., Yellow Springs, OH, USA), while the remaining parameters were measured in laboratory according to the national standard methods [37]. Digital elevation model (DEM) data and land use maps interpreted from 2007 Landsat TM images (30 m resolution) were used to delineate watershed boundaries and measure the land use composition in the Taizi River Basin by ArcGIS 9.2 (ESRI, Redlands, CA, USA). The proportion of nature land, farmland and urban was calculated in ArcGis, in addition to the scope of drainage area for each site (Table A1).

\subsection{Umbrella Species Selection}

The final umbrella species were selected by the calculation of UI index and screening of macroinvertebrate community indices between sites of presence and absence of umbrella species.

\subsubsection{UI Index Calculation}

According to the improved method of identifying umbrella species of American mountain butterfly [11], we measure the potential of each species of macroinvertebrates in the Taizi River Basin to serve as an umbrella for other species.

The UI for each species is calculated as follows:

$\mathrm{UI}=$ median rarity $(R)+$ tolerance values $(T V s)+$ mean percentage of co-occurring species $(P C S)$

$R$ is defined as $1-\left|0.5-Q_{j}\right|, Q_{j}=1-N_{j} / N$ where $N$ is the total number of sites, $N_{j}$ is the number of sites in which species $j$ occurs [38]. $Q$ ranges from 0 (ubiquity) to 1 (rarity).

$T V s$, which are from our laboratory on the calculated values of samples [39], ranges from 0 to 10 . To make the formula into a unified dimension, the TVs are divided by 10 to be standardized from 0 to 1 .

PCS is calculated as follow:

$$
P C S=\sum_{i=1}^{l}\left(\frac{S_{i}-1}{S_{\max }-1}\right) / N_{j}
$$

where $l$ is the number of sites in the data set, $S_{i}$ is the number of species present in each site $i, S_{\max }$ is the total number of species present in all sites in the data set. PCS ranges from 0 (few co-occurring species) to 1 (many co-occurring species).

Potential umbrella species are selected if UI is greater than the mean value of UI plus one standard deviation for all species (i.e., $\mathrm{UI}>$ [UI $\mathrm{Imean}+1 \mathrm{~S} . \mathrm{D}$.$] ).$

\subsubsection{Screening of Macroinvertebrate Community Indices}

In the current study, all sites were divided into two groups according to the presence and absence of presumptive umbrella species respectively. Mann-Whitney U test by SPSS Statistics 19.0 (SPSS Inc., Chicago, IL, USA) was performed to estimate the differences in the biological indices including Shannon diversity $\left(H^{\prime}\right)$, Margalef's richness $(d)$, Simpson diversity $(D)$, Pielou's evenness $(J)$, benthic 
index of biotic integrity $(B-I B I)$, biological monitoring working party score system $(B M W P)$ and Biotic index (BI) between two groups [40-43]. Significance levels of tests were indicated by $p$ values.

\subsection{Protection Levels and Cover Effectiveness}

Managers are expected to focus on effective conservation actions based on umbrella schemes. Here, the umbrella scheme was defined according to the areas or numbers of sites supporting one or more confirmed umbrella species [18]. Each defined umbrella species might occur on various sites and thus have a different coverage of sites. This is represented by Effort (\%), the proportion of the numbers of sites where a confirmed umbrella species occurred among the total number of sites, indicating the level conservation efforts to be devoted. According to the previous study, response currencies, illustrated by Effort $\%$, total occurrence (TO), distribution ratio (DR), partial protection range (PR) and full protection range (FR), have been used to present the umbrella scheme [18]. TO was calculated as the species numbers identified in the sites of an umbrella scheme divided by the total species numbers identified in the whole sampled sites. DR was calculated for each species as the numbers of sites of species $A$ occurred under an umbrella scheme divided by the total numbers of sites of species $A$ actual occurred. There were three cases for each species, i.e., $\mathrm{DR}=0,>0$ or $=100 \%$. If $\mathrm{DR}>0$, PR was calculated as actual numbers of species under an umbrella scheme divided by total numbers of species covered by all confirmed umbrella species, and FR was calculated when the DR $=100 \%$ by the same method. Above all, the protection levels derived from different umbrella schemes provided alternative choices when managers needed to determine the conservation actions. TO, PR and FR changed correspondingly under different composition of sites (Effort\%), and the managers were capable to find out an optimization of sites deemed to be protected.

To test the cover effectiveness for each putative umbrella species, general linear model (GLM) was performed to evaluate the abundance of umbrella species and co-occurred species. All the abundance data were $\log _{\mathrm{e}}$-transformed to meet the assumption normality for GLM $[14,20]$. The linear regressions were performed by Qrigin 8.0 (OriginLab, Northampton, MA, USA).

\subsection{Multivariate Analyses}

In order to explore the relationship between macroinvertebrate communities and environmental variables, the detrended correspondence analysis (DCA) with only the community data and direct gradient analysis were performed successively. DCA was pre-performed to determine the appropriate model for direct gradient analysis, which was whether the canonical correspondence analysis (CCA) or redundancy analysis (RDA) was chosen [44]. For our study, the unimodal model (CCA), was more appropriate (gradient length of DCA $>4$ ) to explore the relationship between communities and environmental data. Prior to CCA, community data were $\log (x+1)$ transformed and environmental data were square root transformed in order to eliminate the influence of extreme values and ensure the data fit normalization. Given the correlation between environmental factors, we used forward selection and the Monte Carlo permutation test (999 permutations) to select a minimum set of variables that had significant and independent effects on the distribution of macroinvertebrate communities during CCA analysis [45]. All the multivariate analyses were performed by CANOCO 4.5 (Microcomputer Power, Ithaca, NY, USA).

\section{Results}

\subsection{Environmental Characteristics}

A summary of the environmental variables at all sampling sites in the Taizi River Basin are presented in Table A1. The substrate in the study area is distributed from sand to boulder. Boulder and cobble are the most common types of bottom characteristics. Flow velocity is mostly moderate despite ranging from lentic water to lotic water. The mean $\mathrm{pH}$ value is 8.09 and meets the national environmental quality standards for surface water in China (GB3838-2002). DO concentrations in most 
sampling sites specify the grade II water quality of GB3838-2002. The mean value of BOD $(8.76 \mathrm{mg} / \mathrm{L})$ exceeds the grade IV water quality. The mean levels of $\mathrm{COD}_{\mathrm{Cr}}$ and $\mathrm{NH}_{3}-\mathrm{N}$ ranged between grade III and IV water quality. The mean value of TN is $3.56 \mathrm{mg} / \mathrm{L}$, much higher than the limit $(2.0 \mathrm{mg} / \mathrm{L}) \mathrm{of}$ grade $\mathrm{V}$ water quality. Both nature land (mean value $=76.3 \%$ ) and farmland (mean value $=20.0 \%$ ) dominate the main land use types and the ratio of the urban is increasing along the longitudinal gradient (mean value $=0.8 \%$ in upper, mean value $=1.9 \%$ in middle, mean value $=7.3 \%$ in lower), indicating increasing human disturbances.

\subsection{Umbrella Species Selection}

A total of 157,502 macroinvertebrates individuals were collected and identified belonging to five phyla (Arthropoda, Mollusca, Annelida, Aschelminthes, Platyhelminthes), nine classes (Insecta, Arachnoidea, Crustacea, Gastropoda, Lamellibranchia, Oligochaeta, Hirudinea, Nematoda, Turbellaria), 24 orders, 69 families, 101 genera and 123 species. Relative abundance of aquatic insects and annelids were $36.5 \%$ and $61.9 \%$. Individuals of other groups were few.

We calculated the UI for each macroinvertebrate species according to the method mentioned above. UI scores of 15 species fell above the cut-off value (UI $\mathrm{Uean}+1 \mathrm{~S} . \mathrm{D} ., 1.53+0.21)$ for umbrella potential (Table 1), and all of the presumptive umbrella species occurred in no less than twenty sites except three species Branchiura sowerbyi, Baetis sp. and Dolichopus sp.. Branchiura sowerbyi were found in nine sites, and Baetis sp. and Dolichopus sp. only in three sites respectively. There were four tolerant species in potential umbrella species including Gammarus sp., Nephelopsis sp., Dolichopus sp. and Branchiura sowerbyi whose tolerance values all exceeded 7.

Table 1. Potential umbrella species and umbrella index (UI) scores.

\begin{tabular}{ccccccc}
\hline Order & Family & Species & $\boldsymbol{R}$ & TVs * & $\boldsymbol{P C S}$ & UI Score \\
\hline Trichoptera & Hydropsychinae & Cheumatopsyche sp. & 0.96 & 0.29 & 0.52 & 1.77 \\
Trichoptera & Hydropsychinae & Hydropsyche orientalis & 0.83 & 0.32 & 0.67 & 1.82 \\
Trichoptera & Hydropsychinae & Hydropsyche nevae & 0.97 & 0.32 & 0.58 & 1.87 \\
Ephemeroptera & Baetidae & Baetis sp. & 0.54 & 0.45 & 0.80 & 1.79 \\
Ephemeroptera & Heptageniidae & Epeorus latifolium & 0.89 & 0.24 & 0.64 & 1.77 \\
Ephemeroptera & Ephemerellidae & Serratella rufa & 0.86 & 0.31 & 0.64 & 1.81 \\
Ephemeroptera & Ephemerellidae & Serratella setigera & 0.87 & 0.32 & 0.62 & 1.81 \\
Ephemeroptera & Ephemerellidae & Ephemerella atagosana & 0.89 & 0.31 & 0.60 & 1.80 \\
Diptera & Ceratopogoniidae & - & 0.77 & 0.46 & 0.53 & 1.76 \\
Diptera & Tipulidae & Antocha sp. & 0.89 & 0.34 & 0.54 & 1.77 \\
Diptera & Dolichopodidae & Dolichopus sp. & 0.54 & 0.78 & 0.47 & 1.79 \\
Amphipoda & Gammaridae & Gammarus sp. & 0.79 & 0.56 & 0.44 & 1.79 \\
Pulmonata & Lymnaeidae & Radix swinhoei & 0.89 & 0.38 & 0.50 & 1.77 \\
Tubificida & Tubificidae & Branchiura sowerbyi & 0.63 & 0.85 & 0.32 & 1.80 \\
Arhynchobdellida & Erpobdellidae & Nephelopsis sp. & 0.81 & 0.55 & 0.48 & 1.84 \\
\hline
\end{tabular}

* TVs were divided by 10. - represents the taxon only identified to the Family level.

There were significant differences between sites by the list of eight putative umbrella species $(p<0.01$, Figure 2) for biotic indices, which provide more information on species identity and the functional roles of individual species as contributors to ecosystem processes and resilience to stress. All eight putative umbrella species have an intermediate degree of ubiquity, respectively occurring in more than 20 sites, and high percentage of co-occurring species (more than 78\%). 

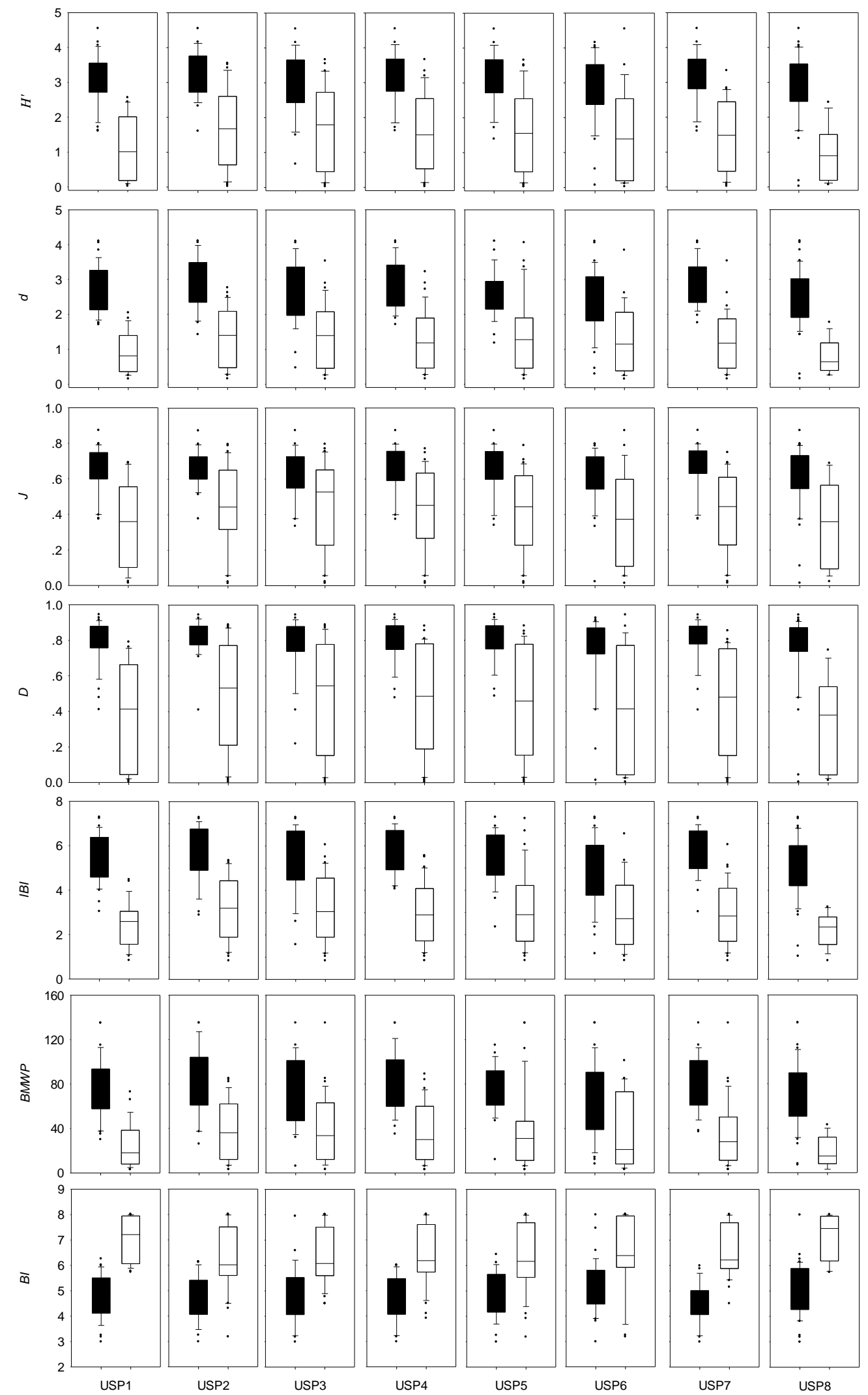

Figure 2. Comparisons for community indices of the presence and absence sites of umbrella species ( $\mathbf{\square}$ : sites where an umbrella species are present; $\square$ : sites where an umbrella species are absent; USP1 to USP8 represent the first Umbrella Species to the eighth one in Table 2). 
Table 2. Ranked UI scores, additive proportion of sampling sites containing top umbrella species (Effort) and additive response currency.

\begin{tabular}{cccccc}
\hline \multirow{2}{*}{ Top Umbrella Species } & UI Score & Effort (\%) & \multicolumn{3}{c}{ Cumulative Response (\%) } \\
\cline { 4 - 6 } & & & TO & PR & FR \\
\hline Hydropsyche nevae & 1.87 & $54 \%$ & $80 \%$ & $87 \%$ & $47 \%$ \\
Hydropsyche orientalis & 1.82 & $57 \%$ & $82 \%$ & $89 \%$ & $52 \%$ \\
Serratella rufa & 1.81 & $58 \%$ & $83 \%$ & $89 \%$ & $54 \%$ \\
Serratella setigera & 1.81 & same & same & same & same \\
Ephemerella atagosana & 1.80 & $61 \%$ & $85 \%$ & $91 \%$ & $59 \%$ \\
Cheumatopsyche sp. & 1.77 & $70 \%$ & $90 \%$ & $93 \%$ & $63 \%$ \\
Epeorus latifolium & 1.77 & same & same & same & same \\
Antocha sp. & 1.77 & $72 \%$ & $90 \%$ & $93 \%$ & $65 \%$ \\
\hline
\end{tabular}

\subsection{Protection Levels and Umbrella Covered Effectiveness}

From minimum to maximum covered sites, there existed several corresponding umbrella species compositions. For example, $54 \%$ of sites (Effort\%) were covered by the first umbrella species, Hydropsyche nevae in Table 2, this was the minimum site coverage and could be regarded as an umbrella scheme mentioned above. Different sites were covered by the second species (Hydropsyche orientalis), except for the $54 \%$ numbers of sites covered by Hydropsyche nevae, there were $3 \%$ of additional sites in the second umbrella scheme. While no umbrella scheme saturation ( $100 \%$ site representation) has been reached after including the following potential umbrella species, protection levels such as proportional accumulation of total occurrence always exceeded increasing levels of effort (Table 2), making it likely that the UI found an optimum solution. Based on partial range, the 70\% effort umbrella schemes missed $7 \%$ of beneficiary species. In other words, when the numbers of potential umbrella species we want to protect increases to a certain extent, more conservation efforts will not have a greater protective effectiveness.

Despite the fact that there were no significant relationships between the abundance of co-occurred species and Hydropsyche nevae $\left(R^{2}=0.04, p>0.05\right)$ and Cheumatopsyche sp. $\left(R^{2}=0.01, p>0.05\right)$, the other cases were significant positive relationships between the abundance of umbrella species and co-occurred ones $(p<0.01)$ (Figure 3$)$. 

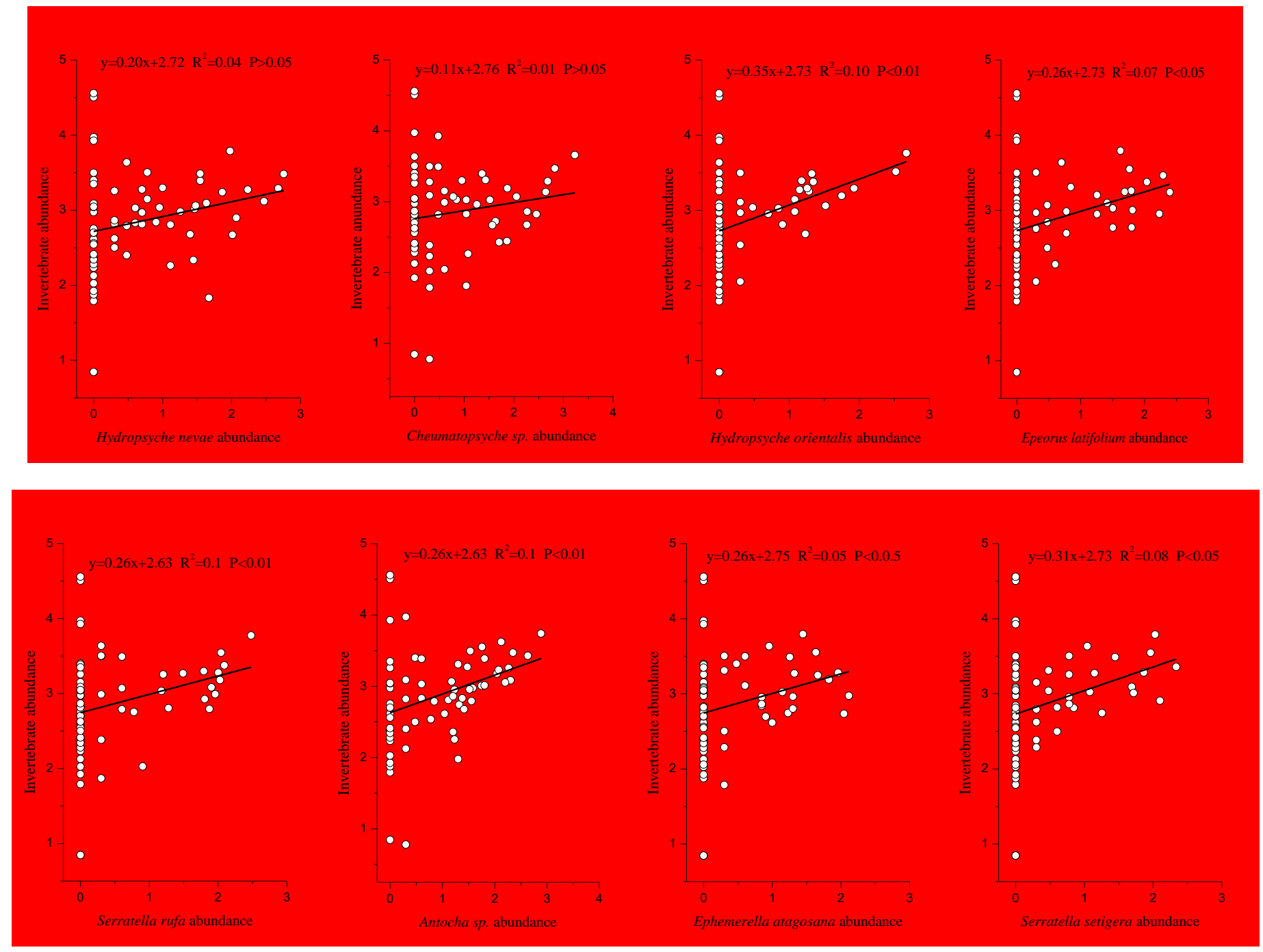

Figure 3. Relationships between species richness and abundance of co-occurring species and abundance of potential umbrella species. 


\subsection{The Relationship Between Macroinvertebrates and Environmental Variables}

We evaluated the relationship between macroinvertebrate species and environmental variables by CCA and Monte-Carlo significance test (Figure 4). Totally, 11 significant variables were obtained, including: elevation, nature land $\%$, farmland $\%$, sand $\%$, pebbles+gravel $\%$, velocity, DO, EC, SS, $\mathrm{NH}_{3}-\mathrm{N}$ and $\mathrm{NO}_{2}-\mathrm{N}$. Environmental variables explained $33.9 \%$ of the variance in macroinvertebrate species by axis- 1 solely, and the cumulative variance explained by the first two axes was $49.7 \%$, which were substantially larger than that of succeeding axes. Farmland\%, sand\%, EC, $\mathrm{SS}, \mathrm{NH}_{3}-\mathrm{N}$ and $\mathrm{NO}_{2}-\mathrm{N}$ were positively correlated with axes 1 . Elevation, nature land $\%$, pebbles+gravel $\%$ and DO were negatively correlated with axis-1. The main variable positively correlated with axis-2 was elevation, and negatively were EC and SS. In the ordination, most of macroinvertebrates species including co-occurring species based on full range were located close to putative umbrella species on the negative side of axis-1, which was characterized by larger natural areas, higher elevation and $\mathrm{DO}$, lower percentage of sand in the substrate, EC, $\mathrm{SS}, \mathrm{NH}_{3}-\mathrm{N}$ and $\mathrm{NO}_{2}-\mathrm{N}$.

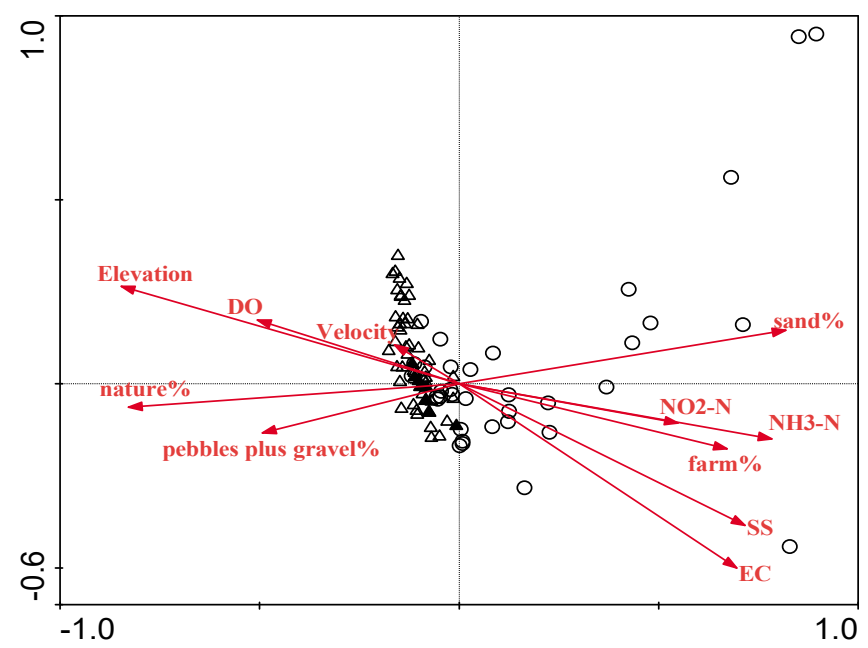

Figure 4. Canonical correspondence analysis (CCA) ordination biplot of distribution of macroinvertebrate species and environmental variables. Different symbols represent the co-existence of species with potential umbrella species based on full range. $\Delta$ : potential umbrella species; $\Delta$ : species co-existing with potential umbrella species; $\bigcirc$ : species not fully co-existing.

\section{Discussion}

It is important to investigate the potential use of the umbrella species approach to guide restoration work for freshwater and riparian ecosystems because of their disproportionate deterioration suffered from anthropogenic habitat degradation and modification [46]. The UI approach has clear applications for nature reserve selection in conservation planning. Umbrella schemes try to balance the conservation demand of species which have higher habitat requirements, such as rare or disturbance-sensitive species, as well as the coverage demand of protecting a higher proportion of sites or landscape where various species with wider distributions reside. These characteristics make the UI different from complementarity algorithms which are strictly based on the amount of species representation to locate optimum site networks [47]. As a quantitative tool of ecological validity, the UI deserves more attention for future conservation policy making and implementation criteria selection.

For the selection of umbrella species, it was important to take into account differences in diversity (i.e., richness or abundance) between areas with and without putative umbrella species $[14,48,49]$. Branton and Richardson reviewed and found that species richness and abundance of co-occurring species were consistently higher in sites where umbrella species were present than where they were not in most previous studies [14]. Given this, we used a modified UI for preliminary selection of macroinverterbrate putative umbrella species, and then compared biotic indices, which 
complemented information on community diversity, integrity and resilience, and tested the significance of differences between sites of presence of putative umbrella species for further selection of appropriate umbrella species. In addition to diversity, community integrity is also an important part of aquatic ecosystem protection and management. Finally, eight umbrella species were selected and shown in Table 2. These eight final species not only reflect the characteristics of umbrella species (including ubiquity, co-existence and sensitivity), but also help to identify areas of high protection values (i.e., high biodiversity, integrated biome structure).

In an umbrella scheme, protection levels should exceed units of conservation effort, such as the proportion of sites included in a conservation network. The protection levels suggested here all exceeded the effort (Table 2). The results were consistent with other quantitative umbrella studies which reported relatively high or near-optimal protection levels $[4,11,16,30,50]$, indicating the adaptability of UI for different taxa and ecosystems. However, nearly 52\% of macroinvertebrate species were found in five or fewer sites. Umbrella species selection may have been interfered by lower frequency of species (i.e., low occurrence rate), which limits co-occurrence. This may be one reason for umbrella scheme saturation (100\% sites representation and protection levels) not being reached after the inclusion of all eight potential umbrella species. In our study, $72 \%$ of sites and $65 \%$ of macroinvertebrate species under full protection were obtained within the inclusion of the eight potential umbrella species. Due to the complex composition, it is hard to cover full habitat sets for different macroinvertebrate groups (aquatic insects, molluscs, crustaceans and annelids) in a river reach. Traits of environmental sensitivity have been taken into the calculation of UI and the screened umbrella species were already labeled with sensitivity to environmental disturbance. Concerning the $35 \%$ of non-co-occurred species, most of them were dragonflies, beetles, leeches and molluscs, which preferred more lentic reaches and had greater tolerance to environmental disturbance [39]. To an extent, the umbrella species screened in our study already meet the conservation demand in a high-biodiversity region.

The general trend of higher abundance of umbrella species was associated with higher abundance of co-occurring species, demonstrates that our results are broadly applicable in the local region. The significant variations in macroinvertebrate abundances and distributions were also explained by environmental variables. Like potential umbrella species, the abundance and distributions of co-occurring species were associated with relatively larger natural areas, higher elevation and $\mathrm{DO}$, lower percentage of sand in the substrate, EC, SS, $\mathrm{NH}_{3}-\mathrm{N}$ and $\mathrm{NO}_{2}-\mathrm{N}$. The association of macroinvertebrate communities with nature land is consistent with the literature, which reports a significant trend linking a relatively low proportion of farmland with more integrated macroinvertebrate community [51]. Obviously, our sampling sites at high altitude are mostly located in forest zone and head-water areas, which are more pristine, while sites at low altitude tend to be in proximity of farmland and urban areas. The associations of potential umbrella species and co-occurring species with higher DO and lower percent sand of substrate are consistent with the researches that reported caddisfly and mayfly larva prefer coarser substrate in lotic habitat with high DO [52-54]. High levels of EC, SS, $\mathrm{NH}_{3}-\mathrm{N}$ and $\mathrm{NO}_{2}-\mathrm{N}$ affect aquatic organisms negatively [55-57]. Regardless of whether the umbrella species are effective or not, the evaluation of habitat, implying the mechanism by which umbrella species can benefit co-occurring species, provides conservation planners valuable insights $[48,58]$.

\section{Conclusions}

Our results suggested that a quantitative umbrella index and empirical testing are needed to evaluate potential umbrella species from aquatic ecosystems and aquatic taxa which have received little attention. Specifically, we cannot verify UI is more useful than other methods on account of lack of prospective techniques for identifying umbrella species for comparison. Compared with random or ad hoc methods, the greatest advantage of UI is that it is based on objective ecological criteria and performs better under realistic circumstances. Limitations linked to the use of single river basin as our study area might apply. Yet, like any other tool for conservation planning, the process of constructing 
an appropriate method for selection of umbrella species must be objective and iterative, and could be scaled up to broader regions.

Author Contributions: All authors listed have contributed to this study. X.G. and S.D. had a substantial involvement in the conception, guidance and revising of the manuscript. The data acquisition and analysis were done by H.W., R.X. and H.-y.D. The manuscript was written by X.G., Q.-q.K. and S.D. All authors have read and agreed to the published version of the manuscript.

Funding: This research was supported by the Special Fund for Basic Scientific Research of Central Public Research Institutes (2020YSKY-003) and the Major Science and Technology Program for Water Pollution Control and Treatment (2018ZX07601001-02).

Acknowledgments: There are many thanks to Xiaodong Qu for identifying macroinvertebrates.

Conflicts of Interest: The authors declare no conflict of interest.

\section{Appendix A}

Table A1. General environmental variables in the Taizi River Basin $(n=69)$ in August 2009.

\begin{tabular}{|c|c|c|c|c|c|c|}
\hline Factor & Variables & Min & Median & $\operatorname{Max}$ & Mean & SD \\
\hline \multirow{5}{*}{ Physical habitat } & Cobble+boulder $\%$ & 0.00 & 57.59 & 98.58 & 49.82 & 31.56 \\
\hline & Pebbles+gravel\% & 0.00 & 21.43 & 77.78 & 24.39 & 20.79 \\
\hline & Sand $\%$ & 0.05 & 3.25 & 100.00 & 25.79 & 40.04 \\
\hline & Depth $(\mathrm{cm})$ & 1.27 & 23.33 & 91.00 & 24.79 & 14.20 \\
\hline & Flow velocity $(\mathrm{m} / \mathrm{s})$ & 0.00 & 0.30 & 14.86 & 0.51 & 1.76 \\
\hline \multirow{6}{*}{ Chemical parameter } & Temp $\left({ }^{\circ} \mathrm{C}\right)$ & 14.00 & 21.00 & 28.10 & 21.17 & 3.25 \\
\hline & $\mathrm{pH}$ & 6.86 & 8.16 & 8.80 & 8.09 & 0.48 \\
\hline & $\mathrm{DO}(\mathrm{mg} / \mathrm{L})$ & 0.00 & 6.45 & 13.50 & 6.44 & 1.96 \\
\hline & $\mathrm{SS}(\mathrm{mg} / \mathrm{L})$ & 8.50 & 112.75 & 979.50 & 193.79 & 221.84 \\
\hline & $\mathrm{TDS}(\mathrm{mg} / \mathrm{L})$ & 51.00 & 313.75 & 995.00 & 365.29 & 210.15 \\
\hline & $\mathrm{EC}(\mathrm{mg} / \mathrm{L})$ & 74.00 & 314.50 & 1230.00 & 420.12 & 279.94 \\
\hline \multirow{3}{*}{ Organic matter } & $\mathrm{BOD}_{5}(\mathrm{mg} / \mathrm{L})$ & 0.00 & 4.60 & 117.50 & 8.76 & 15.75 \\
\hline & $\mathrm{COD}_{\mathrm{Mn}}(\mathrm{mg} / \mathrm{L})$ & 1.40 & 3.30 & 35.05 & 4.95 & 5.18 \\
\hline & $\mathrm{COD}_{\mathrm{Cr}}(\mathrm{mg} / \mathrm{L})$ & 5.10 & 15.20 & 127.50 & 24.23 & 25.30 \\
\hline \multirow{5}{*}{ Inorganic nutrients } & $\mathrm{TP}(\mathrm{mg} / \mathrm{L})$ & 0.03 & 0.10 & 2.63 & 0.23 & 0.41 \\
\hline & $\mathrm{TN}(\mathrm{mg} / \mathrm{L})$ & 0.70 & 2.70 & 17.00 & 3.56 & 2.94 \\
\hline & $\mathrm{NH}_{3}-\mathrm{N}(\mathrm{mg} / \mathrm{L})$ & 0.00 & 0.34 & 13.20 & 1.34 & 2.58 \\
\hline & $\mathrm{NO}_{3}-\mathrm{N}(\mathrm{mg} / \mathrm{L})$ & 0.20 & 1.53 & 7.30 & 1.75 & 1.07 \\
\hline & $\mathrm{NO}_{2}-\mathrm{N}(\mathrm{mg} / \mathrm{L})$ & 0.00 & 0.01 & 0.41 & 0.06 & 0.08 \\
\hline \multirow{3}{*}{ Land use types } & Farmland\% & 0.30 & 16.19 & 61.07 & 19.98 & 12.22 \\
\hline & Nature land $\%$ & 25.59 & 81.32 & 99.70 & 76.28 & 16.26 \\
\hline & Urban\% & 0.00 & 1.57 & 24.12 & 3.74 & 4.94 \\
\hline
\end{tabular}

\section{References}

1. Gaston, K.J. Biodiversity-congruence. Prog. Phys. Geogr. 1996, 20, 105-112. [CrossRef]

2. Oliver, I.; Beattie, A.J. Designing a cost-effective invertebrate survey: A test of the methods for rapid assessment of biodiversity. Ecol. Appl. 1996, 6, 594-607. [CrossRef]

3. Lawton, J.H.; Bignell, D.E.; Bolton, B.; Bloemers, G.F.; Eggleton, P.; Hammond, P.M.; Hodda, M.; Holt, R.D.; Larsen, T.B.; Mawdsley, N.A.; et al. Biodiversity inventories, indicator taxa and effects of habitat modification in tropical forest. Nature 1998, 391, 72-76. [CrossRef]

4. Howard, P.C.; Viskanic, P.; Davenport, T.R.; Kigenyi, F.W.; Baltzer, M.; Dinckson, C.J.; Lwanga, J.S.; Matthews, R.A.; Balmford, A. Complementarity and the use of indicator group for reserve selection in Uganda. Nature 1998, 394, 472-475. [CrossRef]

5. Noss, R.F.; Quigley, H.B.; Hornocker, M.G.; Merrill, T.; Paquet, P.C. Conservation biology and carnivore conservation in the Rocky Mountains. Conserv. Biol. 1996, 10, 949-963. [CrossRef] 
6. Margules, C.R.; Pressey, R.L. Systematic conservation planning. Nature 2000, 405, 243-253. [CrossRef] [PubMed]

7. Landres, P.B.; Verner, J.; Thomas, J.W. Ecological uses of vertebrate indicator species: A critique. Conserv. Biol. 1988, 2, 316-328. [CrossRef]

8. McGeoch, M.A. The selection, testing and application of terrestrial insects as bioindicators. Biol. Rev. Cambridge Philosophical Soci. 1998, 73, 181-201. [CrossRef]

9. Caro, T.M.; O'Doherty, G. On the use of surrogate species in conservation biology. Conserv. Biol. 1999, 13, 805-814. [CrossRef]

10. Wilcox, B.A. In situ conservation of genetic resources: Determinants of minimum area requirements. In National Parks, Conservation and Development; McNeely, J.A., Miller, K.R., Eds.; Smithsonian Institution Press: Washington, DC, USA, 1984; pp. 639-647.

11. Fleishman, E.; Murphy, D.D.; Brussard, P.F. A new method for selection of umbrella species for conservation planning. Ecol. Appl. 2000, 10, 569-579. [CrossRef]

12. Seddon, P.J.; Leech, T. Conservation short cut, or long and winding road? A critique of umbrella species criteria. Oryx 2008, 42, 240-245. [CrossRef]

13. Schoener, T.W. Sizes of feeding territories among birds. Ecology 1968, 49, 123-141. [CrossRef]

14. Branton, M.A.; Richardson, J.S. Assessing the value of the umbrella-species concept for conservation planning with meta-analysis. Conserv. Biol. 2011, 25, 9-20. [CrossRef] [PubMed]

15. Roberge, J.M.; Angelstam, P. Usefulness of the umbrella species concept as a conservation tool. Conserv. Biol. 2004, 18, 76-85. [CrossRef]

16. Lawler, J.J.; White, D.; Sifneos, J.C.; Master, L.L. Rare species and the use of indicator groups for conservation planning. Conserv. Biol. 2003, 17, 875-882. [CrossRef]

17. Hitt, N.P.; Frissell, C.A. A case study of surrogate species in aquatic conservation planning. Aqua. Conserv.: Marine and Freshwater Ecosystems. 2004, 14, 625-633. [CrossRef]

18. Bried, J.T.; Herman, B.D.; Ervin, G.N. Umbrella potential of plants and dragonflies for wetland conservation: A quantitative case study using the umbrella index. J. Appl. Ecol. 2007, 44, 833-842. [CrossRef]

19. Ormerod, S.J.; Durance, I.; Terrier, A.; Swanson, A.M. Priority wetland invertebrates as conservation surrogates. Conserv. Biol. 2010, 24, 573-582. [CrossRef]

20. Branton, M.A.; Richardson, J.S. A test of the umbrella species approach in restored floodplain ponds. J. Appl. Ecol. 2014, 51, 776-785. [CrossRef]

21. Zacharias, M.A.; Roff, J.C. Use of focal species in marine conservation and management: A review and critique. Aqua. Conserv.: Marine and Freshwater Ecosystems. 2001, 11, 59-76. [CrossRef]

22. Roff, J.C.; Evans, S.M.J. Frameworks for marine conservation-non-hierarchical approaches and distinctive habitats. Aqua. Conserv.: Marine and Freshwater Ecosystems. 2002, 12, 635-648. [CrossRef]

23. IUCN. Developing a method for prioritising sites for freshwater biodiversity conservation. In Proceedings of the Report on a workshop organised by the IUCN Freshwater Biodiversity Assessment Programme, IUCN, Gland, Switzerland, 27-29 June 2002.

24. Schmutz, S.; Kaufmann, M.; Vogel, B.; Jungwirth, M.; Muhar, S. A multi-level concept for fish-based, river-type-specific assessment of ecological integrity. Hydrobiologia 2000, 422, 279-289. [CrossRef]

25. Hughes, R.M.; Paulsen, S.G.; Stoddard, J.L. EMAP-surface waters: A multiassemblage, probability survey of ecological integrity in the U.S.A. Hydrobiologia 2000, 422, 429-443. [CrossRef]

26. Launer, A.E.; Murphy, D.D. Umbrella species and the conservation of habitat fragments: A case of a threatened butterfly and vanishing grassland ecosystem. Biol. Conserv. 1994, 69, 145-153. [CrossRef]

27. New, T.R. Are Lepidoptera an effective 'umbrella group' for biodiversity conservation? J. Insect Conserv. 1997, 1, 5-12. [CrossRef]

28. Whiteman, N.K.; Sites, R.W. Aquatic insects as umbrella species for ecosystem protection in Death Valley National Park. J. Insect Conserv. 2008, 12, 499-509. [CrossRef]

29. Freitag, S.; van Jaarsveld, A.S.; Biggs, H.C. Ranking priority biodiversity areas: An iterative conservation valued-based approach. Biol. Conserv. 1997, 82, 263-272. [CrossRef]

30. Fleishman, E.; Blair, R.B.; Murphy, D.D. Empirical validation of a method for umbrella species selection. Ecolo. Appl. 2001, 11, 1489-1501. [CrossRef]

31. Betrus, C.J.; Fleishman, E.; Blair, R.B. Cross-taxonomic potential and spatial transferability of an umbrella species index. J. Environ. Manage. 2005, 74, 79-87. [CrossRef] 
32. Bressler, D.W.; Stribling, J.B.; Paul, M.J.; Hicks, M.B. Stressor tolerance values for benthic macroinvertebrates in Mississippi. Hydrobiologia 2006, 573, 155-172. [CrossRef]

33. Lenat, D.R. A biotic index for the Southeastern United States: Derivation and list of tolerance values, with criteria for assigning water-quality ratings. J. N. Am. Benthol. Soc. 1993, 12, 279-290. [CrossRef]

34. Whittier, T.R.; van Sickle, J. Macroinvertebrate tolerance values and an assemblage tolerance index (ATI) for western USA streams and rivers. J. N. Am. Benthol. Soc. 2010, 29, 852-866. [CrossRef]

35. Kong, W.; Meng, W.; Zhang, Y.; Gippel, C.; Qu, X. A freshwater ecoregion delineation approach based on freshwater macroinvertebrate community features and spatial environmental data in Taizi River Basin, northeastern China. Ecol. Res. 2013, 28, 581-592. [CrossRef]

36. Merritt, R.W.; Cummins, K.W.; Berg, M.B. An Introduction to the Aquatic Insects of North America, 4th ed.; Kendall/Hunt Publishing Company: Dubuque, IA, USA, 2008.

37. National Environmental Protection Bureau (NEPB). Standard Methods for the Examination of Water and Waste-water, 4th ed.; China Environmental Science Publish Press: Beijing, China, 2002. (in Chinese)

38. Baz, A. Ranking species and sites for butterfly conservation using presence-absence data in Central Spain. Nota Lepidopterologica Supplement. 1991, 2, 4-12.

39. Zhao, R.; Gao, X.; Ding, S.; Zhang, Y.; Qu, X.; Liu, S. A study on tolerance values of macroinvertebrate taxa in Liao River basin. Acta Ecologica Sinica. 2015, 35, 1-16. (In Chinese)

40. Magurran, A.E. Measuring Biological Diversity; Blackwell Publishing: Oxford, UK, 2004.

41. Weisberg, S.B.; Ranasinghe, J.A.; Dauer, D.M.; Schaffner, L.C.; Diaz, R.J.; Frithsen, J.B. An estuarine benthic index of biotic integrity (B-IBI) for Chesapeake Bay. Estuaries. 1997, 20, 149-158. [CrossRef]

42. Hilsenhoff, W.L. Rapid field assessment of organic pollution with a family-level biotic index. J. N. Am. Benthol. Soc. 1988, 7, 65-68. [CrossRef]

43. Beck, W.M., Jr. Suggested method for reporting biotic data. Sewage and Industrial Waste. 1955, 27, $1193-1197$.

44. Gao, X.; Niu, C.J.; Chen, Y.S.; Yin, X.W. Spatial heterogeneity of stream environmental conditions and macroinvertebrates community in an agriculture dominated watershed and management implications for a large river (the Liao River, China) basin. Environ. Monit. Assess. 2014, 186, 2375-2391. [CrossRef]

45. ter Braak, C.J.F.; Smilauer, P. CANOCO Reference Manual and CanoDraw for Windows User's Guide: Software for Canonical Community Ordination (Version 4.5); Microcomputer Power: Ithaca, NY, USA, 2002.

46. Sala, O.E.; Chapin, F.S.; Armesto, J.J.; Berlow, E.; Bloomfield, J.; Dirzo, R.; Huber-Sanwald, E.; Huenneke, L.F.; Jackson, R.B.; Kinzig, A.; et al. Global Biodiversity Scenarios for the Year 2100. Science 2000, 287, 1770-1774. [CrossRef]

47. Rodrigues, A.S.L.; Gaston, K.J. Optimization in reserve selection procedures: Why not? Biol. Conserv. 2002, 107, 123-129. [CrossRef]

48. Ozaki, K.; Isono, M.; Kawahara, T.; Iida, S.; Kudo, T.; Fukuyama, K. A mechanistic approach to evaluation of umbrella species as conservation surrogates. Biol. Conserv. 2006, 20, 1507-1515. [CrossRef] [PubMed]

49. Roberge, J.M.; Mikusiński, G.; Svensson, S. The white-backed woodpecker: Umbrella species for forest conservation planning? Biodivers. Conserv. 2008, 17, 2479-2494. [CrossRef]

50. Sergio, F.; Newton, I.; Marchesi, L.; Pedrini, P. Ecologically justified charisma: Preservation of top predators delivers biodiversity conservation. J. Appl. Ecol. 2006, 43, 1049-1055. [CrossRef]

51. Zhang, Y.; Zhao, R.; Kong, W.; Geng, S.; Bentsen, C.N.; Qu, X. Relationships between macroinvertebrate communities and land use types within different riparian widths in three headwater streams of Taizi River, China. J. Freshwater Ecol. 2013, 28, 307-328. [CrossRef]

52. Towns, D.R. The mayflies (Ephemeroptera) of Great Barrier Island, New Zealand: Macro-and micro-distributional comparisons. J. Roy. Soc. New Zealand 1987, 17, 349-361. [CrossRef]

53. Wiggins, G.B.; Mackay, R.J. Some relationships between systematics and trophic ecology in nearctic aquatic insects, with special reference to Trichoptera. Ecology 1978, 59, 1211-1220. [CrossRef]

54. Galbraith, H.S.; Vaughn, C.C.; Meier, C.K. Environmental variables interact across spatial scales to structure trichopteran assemblages in Ouachita Mountain rivers. Hydrobiologia 2008, 596, 401-411. [CrossRef]

55. Hassell, K.L.; Kefford, B.J.; Nugegoda, D. Sub-lethal and chronic salinity tolerances of three freshwater insects: Cloeon sp. and Centroptilum sp. (Ephemeroptera: Baetidae) and Chironomus sp. (Diptera: Chironomidae). J. Exp. Biol. 2006, 209, 4024-4032. [CrossRef]

56. Lemly, D.A. Modification of benthic insect communities in polluted streams: Combined effects of sedimentation and nutrient enrichment. Hydrobiologia 1982, 87, 229-245. [CrossRef] 
57. Delos, C.; Erickson, R. Update of Ambient Water Quality Criteria for Ammonia; EPA/822/R-99/014. Final/Technical Report; Environmental Protection Agency: Washington, DC, USA, 1999.

58. Suter, W.; Graf, R.F.; Hess, R. Capercaillie (Tetrao urogallus) and avian biodiversity: Testing the umbrella-species concept. Conserv. Biol. 2002, 16, 778-788. [CrossRef]

(C) 2020 by the authors. Licensee MDPI, Basel, Switzerland. This article is an open access article distributed under the terms and conditions of the Creative Commons Attribution (CC BY) license (http://creativecommons.org/licenses/by/4.0/). 